\title{
Factors Influencing the Selection of a General Practitioner in South Africa
}

\author{
Richard Shambare \\ Tshwane University of Technology
}

\begin{abstract}
This study investigates factors influencing the choice of a primary health care doctor (PCD) in South Africa. Healthcare is important such that consumers embark on considerable effort when choosing a GP. While it is widely believed that patients' decisions to use a specific PCD is influenced by factors including consultation fees, medical aid accepted, geographic proximity, and third-party referrals, these claims largely remain largely unverified and untested. A PCD choice scale was administered to a sample of 205 healthcare consumers. Results suggest referrals of GP as being important.

Index Terms - doctor, GP, South Africa
\end{abstract}

\section{Introduction}

Patients consider numerous factors when deciding on a specific PCD [1]. It is widely believed that consultation fees, acceptance of medical aid, geographic proximity, and referrals from significant others are important factors in selecting PCDs [2]. Despite many studies on the choice of GPs or PCDs from developing countries, very little studies report on developing countries. To address this paucity, this study investigates factors influencing the choice of PCDs in South Africa. Given the paucity of research in this area, findings from this study will most likely enhance understanding of patient choice behaviour in South Africa, where the number of private health care facilities is increasing [3]. Consequently, there has been growing competitive pressure in the private healthcare sector; resulting in the need to identify new sources of competitive advantage [2]. Thus, identifying factors influencing PCD choice presents itself as an important research topic.

Given that what is known about PCD choice behaviour emanates from the developed world, local GPs lack actionable variables to inform their marketing strategy. Although this intelligence is available, it falls short to devise effective strategy.

\section{Literature Review}

Healthcare in South Africa

At the inception of democracy in 1994, healthcare in South Africa was made "free for all" at public health care facilities [4]. The latter authors demonstrate the challenges faced in providing quality 'free' health care for a growing nation emerging from apartheid. The conditions of the country's government hospitals failed to cope with the increasing population.

The challenges experienced in public health created opportunities for the private sector. Since then, there has been an exponential growth in private health care facilities. These, however, only catered for those with medical aid or could pay for healthcare [2]. Nyandoro [3] explains that because of the better service offered in the private sector, a significant proportion of South Africans prefer utilising the services of private primary healthcare facilities primarily because of they get faster and friendlier service. Consequently, there has been increasing competition in the private healthcare sector.

The choice of a health care practitioner is influenced by numerous factors. Accessing healthcare can either be an individual's independent decision or a communal event. Hosftede's cultural dimensions best illustrates this phenomena [5]. Furthermore, differences in the structure of healthcare systems in countries was also observed as having some influence of which factors are important in choosing a PCD [1]. All the same, factors influencing the choice of PCD range from one's society, religious belief, or even medical aid membership to doctor's personal characteristics, professionalism, and office management [1] and perceived level of satisfaction [2, 3].

Although information relating to how patients make decisions is important, research has until recently overlooked this phenomenon. The literature shows that most studies revolved around the decision-making abilities of medical practitioners [6]. Of the studies focusing on patients' decisionmaking, they look at how patients' provision of informed consent, therapeutic choice, and end-of-life decisions [1]. Very little attention was placed on patients' behavioural decision making processes. In South Africa, the focus is mostly on patient satisfaction, for instance the studies by Peer and Mpinganjira [2] and Nyandoro [3].

Bornstein et al [1] developed a scale measuring the importance of 23 factors in choosing a PCD. From these, three key factors were important for patients in determining the choice of a PCD were observed. These related to: (1) PCDs' professional skills, which included aspects like registration with a certification board, treatment of patients and including any lawsuits or complaints pending. (2) PCDs' office management involves the number of doctors in the office and proximity of the office to shopping malls. (3) PCDs' personal characteristics, which refers to the doctor's age, gender, and ethnicity. It was therefore opportune to test this scale in South Africa to assess its widespread applicability.

\section{Methodology}

A survey method was used to collect data from primary health care consumers from shopping malls from two provinces in South Africa in Gauteng (Johannesburg and Pretoria) and Limpopo (Polokwane). Using non-probabilistic sampling methods [7], four research assistants helped with 
administering the instrument. The research assistants were positioned at strategic places in shopping malls - close to restaurants, hair salons, and parking pay points from where they solicited respondents to complete the self-administered questionnaires.

Mall-intercept sampling was preferred because it allows for reaching a more representative sample, as individuals in malls usually represent a wide range of consumers from different backgrounds and taste [8]. In total 300 questionnaires were distributed. Of these, 277 questionnaires were returned and only 205 were fully completed and usable for analysis, representing a response rate of about 68 per cent. Table 1 illustrates the participants' demographic characteristics.

\section{Results}

\subsection{Sample demographic profile}

As illustrated in Table 1, a majority (61 per cent) were male. In terms of ethnicity, a vast majority, 83 per cent were black. Those with up to high school education were also the majority (59 per cent).

Table 1: Demographic profile

\begin{tabular}{|l|l|c|}
\hline \multicolumn{2}{|c|}{ Demographic Characteristics } & Per cent (\%) \\
\hline \multirow{4}{*}{ Gender } & Male & 61 \\
\cline { 2 - 3 } & Female & 39 \\
\hline \multirow{5}{*}{ Age } & $<20$ years old & 18 \\
\cline { 2 - 3 } & $20-29$ years old & 34 \\
\cline { 2 - 3 } & $30-39$ years old & 32 \\
\cline { 2 - 3 } & $40+$ years old & 16 \\
\hline \multirow{5}{*}{ Education } & High School & 59 \\
\cline { 2 - 3 } & Degree & 15 \\
\cline { 2 - 3 } & Postgraduate & 26 \\
\hline
\end{tabular}

Participants were asked to rate on a Likert scale ( $1=$ Strongly Disagree; $5=$ Strongly Agree) on the importance of the 22 items used in this study. Recommendation of GPs was rated as being the most important followed by their area of specialisation. The least important factor was doctor's registration with the HPCSA, the South African certification board for health practitioners. The second-least important was whether the doctors had malpractice cases filed against them. This appears sensible, given that if one is using a doctor that recommended by a friend, they will continue using the same doctor and will more than likely recommend the doctor to other friends and family. Over time, the specific doctor's treatment history as well as success rate and also complaints and lawsuits will be communicated in the recommendations and testimonials to friends.

According to Bornstein et. al [1], the PCP scale contains three subscales: doctors' professional skills, office management, and personal characteristics. To establish the factors related to GP's choice, factor analysis was performed.
Diagnostics for factor analysis were satisfactory $(\mathrm{KMO}=$ 0.798; Bartlett's Test of Sphericity $X^{2}=1187.9 ; p<0.000$ ) [9]. Subsequently, a five-factor solution explaining 65 per cent of the variance was extracted. Compared to Bornstein and colleagues' results, our findings yielded two extra factors above the original three in their study. However, the essence of Bornstein et al. [1] most important factors was captured in these results and thus we did not view such as a worrisome divergence from theory. It was also observed that the professionalism construct, as postulated by Bornstein's study was captured within the first two factors of this study. Again, consistent with the latter study, items relating to office management and doctors' personal characteristics were observed to fall within the same order (office management first followed by personal characteristics) in this study as well.

\section{Discussion \& Concluding Remarks}

More importantly, the socio-cultural difference between the United States sample (in Bornstein et el., [1]) and the present study's South African sample may explain these differences [5]. Firstly, the US is a developed economy whose population is more educated than the South African population. Secondly, and because of this level of development, there is a wider access to health care providers in the US. With greater access, consumers exercise a greater degree of autonomy when selecting primary health care providers. The individuals' mechanics to evaluate these in a developed society are different and easily summarised and classified into three categories (or sub-scales): professional skills, office management, and personal characteristics. Whereas in a developing country such as South Africa, where exposure and education levels are relatively lower, consumers rely more on referrals and word-of-mouth testimonials of health care providers from friends and family. Another significant consideration is that South Africans, in general, are more collectivistic individuals as opposed to Americans who exhibit more individualistic tendencies [5]. This implies that in the US, an individual's own judgement and evaluation of a GP is sufficient. However, in environments where individual opinions tend to be subservient to those of the society, the referral mechanism takes precedence and often does bring in additional factors to consider in the choice of a GP.

\section{References}

[1] Bornstein, B.H., D. Marcus, and W. Cassidy, Choosing a doctor: an exploratory study of factors influencing patients' choice of a primary care doctor. Journal of Evaluation in Clinical Practice, 2000. 6(3): p. 255-262.

[2] Peer, M. and M. Mpinganjira, A gap analysis of service expectations and perceptions in private general practice. African Journal of Business Management, 2012. 6(1): p. 297-305.

[3] Nyandoro, P., Service Quality and Patient Satisfaction in Private Hospitals: A Case of a Private Hospital in Pretoria, in Business School, 2012, Tshwane University of Technology: Tshwane.

[4] Kautzky, K. and S.M. Tollman, A perspective on primary health care in South Africa, 2010, School of Public Health, University of Witwatersrand: Johannesburg. 
[5] Hofstede, G., What did GLOBE really measure? Researchers' minds versus respondents' minds. Journal of International Business Studies, 2006. 2006 (37): p. 882-896.

[6] Christensen, C., et al., Pervasiveness of framing effects among physicians and medical students. Journal of Behavioral Decision Making, 1995. 8: p. $169-180$.

[7] Kerlinger, F.N. and H.B. Lee, Foundations of Behavioural Research, 4th edition2000, Sydney: Harcourt College Publishers.
[8] Calder, B.J., L.W. Phillips, and A.M. Tybout, Designing Research for Application. Journal of Consumer Research, 1981. 8(2): p. 197-207.

[9] Field, A., Discovering Statistics Using SPSS, 3rd Edition2009, Thousand Oaks, CA: Sage. 